\title{
Letter to a Friend
}

\section{Dear Andrew,}

I talked to you last on Wednesday night. We spent half an hour together as we had done several times before. Nothing strange or unusual, I must say. The only difference was that instead of sitting in your office at Barts or in mine at the Middlesex, I was listening to you in your bedroom. "Nothing to worry about" you said "I feel all right. It is just a matter of a few days and I will be completely recovered." You had been saying this for the past 12 months and I believed you.

In this life does it always help to face reality? Why should we be cool-minded and rational all the time? We both wanted to believe in this unbelievable idea, didn't we? And this helped us to carry on for another few days. We could have wasted those remaining moments and that indeed would have contradicted whatever we had been saying and doing all those years.

I still remember when we first met - you said "Boy, let's join forces. It will be fun" and let me tell you now, it was more than fun. All the potential was there, but you proved more than anyone else that the "talkers' do not go very far - only the 'doers' succeed and achieve something important. You were obsessed by a basic idea: you wanted to find out something relevant, something that could open new frontiers in our poor understanding of the many 'mysterious' facts, by which we are constantly surrounded. You strongly wanted this, and there is no doubt you achieved your goal.

Flying to America a few days later, it occurred to me that one day I might be asked to write something about you. It was only last summer when I introduced you at the Juvenile Diabetes Foundation Research Award. Wasn't it funny? I remember I started my 'official speech' by saying "Dear Organizing Committee, how can anyone be asked to introduce one of his brothers ...?" Everyone laughed, but very few people in the audience understood my serious embarrassment.

It is one thing to talk - everyone will soon forget - but it is totally different when one has to write something. It lasts for ever. "No", I promised to myself, when the first drink was served, "I shall never do it."

Imagine if I ever had to record your scientific achievements for an audience of diabetologists. They have already heard you talk so many times: they have already corresponded with their Editor-in-Chief of Diabetologia on so many occasions, that it would sound absolutely superfluous. They know about your contributions to the genetics of diabetes and the possible role of environmental and immunological events in causing beta cell damage. What is the point of re-emphasizing your original ideas to look for genetically and immunologically predisposed individuals? They all know that this is a fundamental step in trying to understand the basic mechanisms causing diabetes and the potential for preventive therapeutic intervention. No, that would certainly be repetitive and definitely sound boring. I will never do that, I promise.

This fantasy was suddenly interrupted when dinner was served, and I blamed my Italian imagination for such strange ideas in my mind. "Don't you worry, Andrew" I said to myself "We still have a long, long way to go."

Telephone calls in the middle of the night are often couriers of bad news. The following Monday night was no exception to this sinister rule. It was the 12th of October 1982 when you died. 